\title{
Analytic thinking reduces belief in conspiracy theories
}

\author{
Viren Swami $^{\mathrm{a}, *}$, Martin Voracek ${ }^{\mathrm{b}}$, Stefan Stieger ${ }^{\mathrm{b}, \mathrm{c}}$, Ulrich S. Tran ${ }^{\mathrm{b}}$, Adrian Furnham ${ }^{\mathrm{d}}$ \\ ${ }^{a}$ Department of Psychology, Faculty of Science and Technology, University of Westminster, London, UK \\ ${ }^{\mathrm{b}}$ Department of Basic Psychological Research and Research Methods, School of Psychology, University of Vienna, Vienna, Austria \\ ${ }^{\mathrm{c}}$ Research Methods, Assessment, and iScience, Department of Psychology, University of Konstanz, Konstanz, Germany \\ ${ }^{\mathrm{d}}$ Department of Clinical, Educational, and Health Psychology, Division of Psychology and Language Science, University College London, London, UK
}

\section{A R T I C L E I N F O}

\section{Article history:}

Received 8 May 2014

Revised 7 August 2014

Accepted 8 August 2014

\section{Keywords:}

Conspiracy theories

Analytic thinking

Experiential thinking

Open-mindedness

Thinking dispositions

\begin{abstract}
A B S T R A C T
Belief in conspiracy theories has been associated with a range of negative health, civic, and social outcomes, requiring reliable methods of reducing such belief. Thinking dispositions have been highlighted as one possible factor associated with belief in conspiracy theories, but actual relationships have only been infrequently studied. In Study 1, we examined associations between belief in conspiracy theories and a range of measures of thinking dispositions in a British sample $(N=990)$. Results indicated that a stronger belief in conspiracy theories was significantly associated with lower analytic thinking and open-mindedness and greater intuitive thinking. In Studies 2-4, we examined the causational role played by analytic thinking in relation to conspiracist ideation. In Study $2(N=112)$, we showed that a verbal fluency task that elicited analytic thinking reduced belief in conspiracy theories. In Study $3(N=189)$, we found that an alternative method of eliciting analytic thinking, which related to cognitive disfluency, was effective at reducing conspiracist ideation in a student sample. In Study 4, we replicated the results of Study 3 among a general population sample $(N=140)$ in relation to generic conspiracist ideation and belief in conspiracy theories about the July 7, 2005, bombings in London. Our results highlight the potential utility of supporting attempts to promote analytic thinking as a means of countering the widespread acceptance of conspiracy theories.
\end{abstract}

(c) 2014 Elsevier B.V. All rights reserved.

\section{Introduction}

Conspiracy theories can be described as "a subset of false beliefs in which the ultimate cause of an event is believed to be due to a plot by multiple actors working together with a clear goal in mind, often unlawfully and in secret" (Swami \& Furnham, 2014, p. 220). For example, conspiracy theories relating to the disappearance of Amelia Earhart and Fred Noonan propose that, rather than crashing at sea, the Japanese military downed their aircraft as

\footnotetext{
* Corresponding author. Address: Department of Psychology, Faculty of Science and Technology, University of Westminster, 309 Regent Street, London W1B 2UW, UK. Tel.: +44 2079115000.

E-mail address: v.swami@westminster.ac.uk (V. Swami).
}

they were spying on the Japanese in the Pacific at the request of the Roosevelt administration (Swami \& Furnham, 2012). Such conspiracy theories are widespread: using four nationally representative surveys, sampled between 2006 and 2011, Oliver and Wood (2014a) reported that half of the American public endorsed at least one conspiracy theory. From this perspective, a conspiratorial worldview appears to be a relatively widespread tendency across ideological spectra, rather than the aberrant expression of political extremists or the outcome of psychopathological minds (for a review, see Swami \& Furnham, 2014).

In addition to being widespread, conspiracy theories have negative social, health, and civic outcomes. For example, although belief in conspiracy theories may foster 
greater political transparency (Swami \& Coles, 2010) and allow actors to challenge dominant ideological structures (Sapountzis \& Condor, 2013), there is also evidence that exposure to conspiracy theories reduces intention to engage in politics, to reduce one's carbon footprint (Jolley \& Douglas, 2014a), to vaccinate (Jolley \& Douglas, 2014b; Kata, 2010), and to engage in positive health behaviours (Oliver \& Wood, 2014b). In addition, belief in conspiracy theories has been associated with riskier sexual attitudes and behaviours in diverse samples (e.g., Ford, Wallace, Newman, Lee, \& Cunningham, 2013; Gaston \& AlleyneGreen, 2013; Hutchinson et al., 2007), less egalitarian human rights attitudes (Swami et al., 2012), racist attitudes (Baer, 2013; Swami, 2012), and political violence (Bilewicz, Winiewski, Kofta, \& Wójcik, 2013).

Given these issues, understanding the psychosocial origins of belief in conspiracy theories remains an important task for scholars. To this end, a small body of work has examined the form and content of conspiracy theories (e.g., Bost \& Prunier, 2013; Raab, Auer, Ortlieb, \& Carbon, 2013; van Prooijen \& Jostmann, 2013), the context in which conspiracy theories flourish (e.g., GrzesiakFeldman, 2013; Warner \& Neville-Shepard, 2014), and the linguistic styles of conspiracy theorists (e.g., Wood \& Douglas, 2013). Concurrently, a larger body of research has focused on individual difference correlates of belief in conspiracy theories, overturning an earlier approach that attempted to pathologise such beliefs (e.g., Groh, 1987; Robins \& Post, 1997). This perspective is based on the notion that it is possible to measure conspiracist ideation as an individual difference trait (Brotherton, French, \& Pickering, 2013; Bruder, Haffke, Neave, Nouripanah, \& Imhoff, 2013), which in turn will be correlated with other psychological antecedents.

Thus, studies have reported relatively reliable associations between stronger belief in conspiracy theories and a number of psychological constructs, such as greater distrust in authority, higher political cynicism, lower selfesteem, greater authoritarianism, and paranormal beliefs (Abalakina-Paap, Stephan, Craig, \& Gregory, 1999; Brotherton et al., 2013; Bruder et al., 2013; Imhoff \& Bruder, 2013; Stieger, Gumhalter, Tran, Voracek, \& Swami, 2013; Swami, 2012; Swami, Chamorro-Premuzic, \& Furnham, 2010; Swami \& Furnham, 2012; Swami et al., 2011). In addition, several studies have examined associations between belief in conspiracy theories and the Big Five personality domains, but results have been equivocal with some studies reporting significant associations with Openness to Experience and Agreeableness (Furnham, 2013; Swami \& Furnham, 2012; Swami et al., 2010, 2011, 2013) and others reporting weak or no significant associations (Brotherton et al., 2013; Bruder et al., 2013; Imhoff \& Bruder, 2013).

Another class of studies has focused on reasoning biases and heuristics in conspiracist ideation (McHoskey, 1995). Clarke (2002), for example, proposed that belief in conspiracy theories could be explained in terms of the fundamental attribution error: conspiracy theorists, he suggested, are more likely to make a dispositional inference about personified actors, even when adequate situational explanations are available. Other scholars have reported that conspiracist beliefs may be a product of a representativeness heuristic, that is, a tendency to accept explanations that are proportional to the consequences of an event (Leman \& Cinnirella, 2007). Most recently, Brotherton and French (2014) found that belief in conspiracy theories was associated with susceptibility to the conjunction fallacy, that is, an error of probabilistic reasoning where individuals overestimate the likelihood of co-occurring events.

These studies point to reasoning biases as a possible antecedent of belief in conspiracy theories, but it is also possible they reflect broader associations with cognitive ability. For example, some research has indicated that performance on tasks of heuristics and biases is modestly related cognitive ability (e.g., Stanovich \& West, 1999, 2000); cognitive ability, in turn, is associated with belief in conspiracy theories (Swami et al., 2011; see also Swami \& Furnham, 2012), which hints at a possible mediatory link. Another possibility is that the association between susceptibility to biases and heuristics and conspiracist ideation is underpinned by thinking dispositions that shape how individuals seek, interpret, and contest the legitimacy of evidence (Leman, 2007). Certainly, performance on tasks of heuristics and biases have been found to be modestly correlated with thinking dispositions (e.g., West, Toplak, \& Stanovich, 2008), but associations between the latter and conspiracist ideation have been infrequently studied.

In one study, Leman and Cinnirella (2013) examined associations between belief in conspiracy theories and need for cognitive closure (i.e., a preference for order and structure, closed-mindedness, and discomfort with ambiguity), but reported no significant correlation $(r=-.05$, $N=30$ ). On the other hand, there is evidence that those aspects of schizotypy that mirror disorganised thought processes and a rejection of analytic information generation are significantly associated with belief in conspiracy theories (Barron, Morgan, Towell, Altemeyer, \& Swami, 2014; Darwin, Neave, \& Holmes, 2011). Relatedly, a growing body of evidence suggests that belief in conspiracy theories is associated with the rejection of scientific findings, particularly but not limited to climate change (e.g., Lewandowsky, Gignac, \& Oberauer, 2013; Lewandowsky, Oberauer, \& Gignac, 2013), as well as belief in contradictory statements (Wood, Douglas, \& Sutton, 2012). Other work has shown that analytic, cognitively-focused inoculation messages are effective at reducing the effectiveness of conspiracy theories (Banas \& Miller, 2013). More broadly, commentators have highlighted the importance of different thinking dispositions - particularly the ability to think critically - as a means of helping individuals recognise, understand, and avoid prioristic conspiracist messages (e.g., Blair, 2012).

Thus, while thinking dispositions may seem to be, conceptually at least, a plausible antecedent of belief in conspiracy theories, evidence of associations to date have been equivocal and piecemeal. In the present study, then, we adopted two complementary strategies to examine whether individual differences in thinking dispositions are associated with belief in conspiracy theories. Study 1 was a correlational study with British participants, in which we examined associations between belief in 
conspiracy theories and scores on a range of measures of thinking dispositions that we identified as being potentially relevant. Next, to establish causation, we examined whether an experimental manipulation that is known to increase analytic processing would reduce general belief in conspiracy theories (Study 2). In Study 3, we tested for robustness using an alternative experimental technique also known to increase analytic processing. Finally, in Study 4, we examined whether increasing analytic processing of information would also reduce belief in a specific conspiracy theory, as opposed to general belief in conspiracy theories.

\section{Study 1}

Study 1 was a correlational study that examined associations between belief in conspiracy theories and a broad range of thinking dispositions that we identified as being potentially relevant. First, one of the most appealing psychological theories for understanding conspiracy theories is the notion of two independent information processing systems (e.g., Chaiken, 1980; Denes-Raj \& Epstein, 1994; Petty \& Cacioppo, 1984), namely an experiential or intuitive system (fast, automatic, governed by habit, susceptible to affective reactions, and difficult to control consciously) and an analytic or rational system (conscious, deliberate, effortful, slow, affectively-neutral, and rule-based). Of the two systems, it is the experiential system that will likely show a significant positive correlation with belief in conspiracy theories. Not only does this system enhance reliance on feelings evoked by information (and conspiracy theories are often affect-laden; Sunstein \& Vermeule, 2009), it is also positively associated with traits that are known to be associated with conspiracist ideation (e.g., Agreeableness; Pacini \& Epstein, 1999) and a preference for heuristic solutions (Epstein, Pacini, Denes-Raj, \& Heier, 1996). On the other hand, an analytic thinking style should be negatively associated with belief in conspiracy theories, as it prompts more careful information processing, thereby increasing attention on content and evidence (Chaiken, Liberman, \& Eagly, 1989). In addition, this thinking style is associated with measures that are negatively associated with belief in conspiracy theories (e.g., selfesteem; Pacini \& Epstein, 1999; Pacini, Muir, \& Epstein, 1998) and with correct normative responses on tests of cognitive bias (Epstein et al., 1996).

Besides information processing styles, another thinking disposition that may be associated with belief in conspiracy theories is the dimension of open-mindedness (which should not be confused with the Big Five facet of Openness to Experience). Stanovich and West (1997) described openminded thinking as a tendency to favour contemplative over impetuous behaviour, a tendency to analyse options and alternative perspectives, questioning one's own assumptions, and welcoming different possibilities. Actively-open minded thinking includes the notion of flexibility, outward seeking of knowledge, and openness, which have been highlighted as cornerstones of critical thinking (Baron, 2008). In one previous study of children (Kokis, Macpherson, Toplak, West, \& Stanovich, 2002), thinking dispositions as measured through open-minded thinking and need for cognition was significantly associated with analytic reasoning, once the effects of cognitive ability was controlled. As such, it stands to reason that there will be a negative association between actively-open minded thinking and belief in conspiracy theories.

In a similar vein, need for cognition may be another useful predictor of individual differences in conspiracist ideation. Need for cognition refers to dispositional differences in cognitive motivation and reflects an intrinsic motivation to engage in and enjoy effortful cognitive endeavours (Cacioppo \& Petty, 1982; Cacioppo, Petty, Feinstein, \& Jarvis, 1996). Individuals who score highly on need for cognition are more likely to attend to, elaborate, evaluate, and recall information (e.g., Peltier \& Schibrowsky, 1994) and less dogmatic (Cacioppo \& Petty, 1982), which hints at a possible negative association with belief in conspiracy theories. In contrast, a need for closure can be defined as a desire for "an answer on a given topic, any answer... compared to confusion and ambiguity" (Kruglanski, 1990; p. 337), which suggests a positive relationship with belief in conspiracy theories. Although Leman and Cinnirella (2013) failed to find a significant association between these variables in their study, we included need for cognition in the present work to examine associations using a larger sample.

In short, in Study 1, we sought to examine the extent to which individual differences in thinking dispositions are associated with belief in conspiracy theories. The focus on thinking dispositions is unlikely to be misplaced: these dispositions not only provide an indication of what individuals are able to do, but also how they typically invest their cognitive abilities (Perkins, Tishman, Ritchhart, Donis, \& Andrade, 2000). Broadly speaking, thinking dispositions can be viewed as a constraint of the cognitive system that has the potential to shape information processing and assimilation of illogical, contradictory, or factually incorrect arguments. Here, we predicted that belief in conspiracy theories would be positively associated with experiential thinking styles and need for closure, and negatively associated with an analytic thinking style and need for cognition.

\subsection{Method}

\subsubsection{Participants}

The participants of this study were 990 British residents (560 women, 430 men) recruited from the community in London, UK. Participants ranged in age from 18 to 71 years $(M=32.79, S D=13.99)$. The majority of the sample was of British White descent (93.5\%) and, in terms of educational qualifications, $13.4 \%$ had completed minimum secondary schooling, $24.4 \%$ were still in full-time education, $39.0 \%$ had an undergraduate degree, $13.7 \%$ had a postgraduate degree, and the remainder had some other qualification.

\subsubsection{Materials}

2.1.2.1. Belief in conspiracy theories. To measure general conspiracist ideation or belief in conspiracy theories, we used the Belief in Conspiracy Theories Inventory (BCTI; Swami et al., 2010, 2011), which consists of 15 items that 
describe a range of prominent conspiracy theories (sample item: 'A powerful and secretive group, known as the New World Order, are planning to eventually rule the world through an autonomous world government, which would replace sovereign governments'). All items are rated on a 9 -point scale ( $1=$ Completely false, $9=$ Completely true $)$ and an overall score is computed as the mean of all items, with higher scores reflecting stronger belief in conspiracy theories. Scores on this measure have been shown to have a one-dimensional factor structure with good internal consistency (Swami et al., 2010, 2011) and are very strongly correlated with scores from a generic measure of conspiracist ideation ( $r=.88$; Brotherton et al., 2013). In the present work, Cronbach's $\alpha$ for this measure was .91.

\subsubsection{Experiential and analytic thinking styles. Participants} completed the 42-item Rational/Experiential Multimodal Inventory (REIm; Norris \& Epstein, 2011), a revision of the Rational-Experiential Inventory (REI; Epstein et al., 1996). The REIm contains 12 items that measure an analytic thinking style (a tendency to solve problems through understanding of logical principles and the evaluation of evidence; sample item: 'I enjoy problems that require hard thinking') and 30 items that measure an experiential thinking style. The latter consists of three 10-item subscales, namely Intuition (a tendency to solve problems intuitively and based on affect; sample item: 'I often go by my instincts when deciding on a course of action'), Emotionality (a preference for intense and frequent strong affect; sample item: 'I'd rather be upset sometimes and happy sometimes, than always feel calm'), and Imagination (a tendency to engage in, and appreciate, imagination, aesthetics productions, and imagery; sample item: 'I have favourite poems and paintings that mean a lot to me'). All items are rated on a 5 -point scale $(1=$ Strongly disagree, $5=$ Strongly agree) and subscale scores are computed as the mean of associated items. Norris and Epstein (2011) reported that these subscales have good discriminant validity and acceptable internal consistency coefficients. Cronbach's $\alpha$ coefficients in the present study were as follows: Rational, .86; Intuition, .74; Emotionality, .76; Imagination, .72.

\subsubsection{Open-minded thinking. To measure open-minded} thinking, we used the Actively-Open Minded Thinking scale (AOT; Stanovich \& West, 2007). Although there have been multiple versions of the AOT scale (e.g., Stanovich \& West, 1997; Sá, West, \& Stanovich, 1999) consisting of different combinations of items and subscales, the most current version includes 41 items that measure facets of open-minded thinking, including flexible thinking, openness, dogmatism, categorical thinking, belief identification, and counterfactual thinking (sample item: 'People should always take into consideration evidence that goes against their beliefs'). Items are rated on a 6-point scale ( $1=$ Strongly disagree, $6=$ Strongly agree $)$. Although there is some debate as to the factor structure of the AOT (Marsh \& Pastor, 2011), Stanovich and West (2007) suggest calculating an AOT scale total score by averaging participant responses across all 41 items, such that higher scores reflect more actively open-minded thinking. They report that the total score has good internal consistency coefficients and provide evidence of adequate convergent validity. In the present study, Cronbach's $\alpha$ for this measure was .76 .

2.1.2.4. Need for cognition. Need for cognition was measured using the 18-item Need for Cognition Scale (NCogS; Cacioppo et al., 1996). This scale measures dispositional differences in intrinsic motivation to engage in and enjoy effortful cognitive endeavours (sample item: 'The notion of thinking abstractly is appealing to me'). Items are rated on a 6-point scale ( 1 = Strongly disagree, $6=$ Strongly agree $)$ and an overall score is computed as the mean of all items. Higher scores on this scale reflect greater need for cognition. The scale has been shown to have acceptable psychometric properties (Cacioppo et al., 1996), including good internal consistency coefficients (West et al., 2008). In the present study, Cronbach's $\alpha$ for this scale was .84 .

2.1.2.5. Need for closure. Participants were asked to complete a brief version of the Need for Closure Scale (NCloS; Roets \& van Hiel, 2011). This is a 15 -item revision of the revised 41-item Need for Closure Scale (Roets \& van Hiel, 2007) that assesses an individual's inclination to 'seize' on closure quickly and a desire to maintain or 'freeze' on closure (sample item: 'I don't like situations that are uncertain'). All items were rated on a 5 -point scale ( $1=\mathrm{Com}$ pletely disagree, $5=$ Completely agree). An overall score is computed as the mean of all items, with higher scores on this scale reflecting greater need for closure. Evidence of good psychometric properties for the brief $\mathrm{NCloS}$ was provided by Roets and van Hiel (2011). In the present study, Cronbach's $\alpha$ for this measure was .89 .

2.1.2.6. Demographics. Participants provided their demographic details consisting of sex, age, ethnicity, and highest educational qualifications.

\subsubsection{Procedure}

Ethics approval for all studies reported here was obtained from the relevant university ethics committee. Eight research assistants trained in psychological methods recruited participants opportunistically from several public locations in Greater London. Potential participants who met inclusion criteria (of adult age and resident in Britain) were invited to take part in a study on their thinking styles and were provided with an information sheet that briefly described the study. Once participation had been agreed, participants provided written informed consent and completed an anonymous paper-and-pencil survey in a quiet location setup for the purposes of the study. The order of presentation of the above scales in the survey was pre-randomised for each participant. Upon completion and return of the survey, participants were provided with a debrief sheet that contained further information about the study and the contact information of the first author. All participants took part on a voluntary basis and were not remunerated for participation. 


\subsection{Results and discussion}

Missing data (less than $2 \%$ of the total dataset) were replaced using the mean replacement technique. Descriptive statistics ( $M$ and $S D$ ) for, and bivariate correlations between, all variables included in this study are reported in Table 1. As can be seen, belief in conspiracy theories was significantly negatively correlated with an analytic thinking style and open-minded thinking, and positively correlated with intuitive thinking style and need for closure. In general, correlations between belief in conspiracy theories and thinking styles were of a small-to-medium effect size, while those with open-minded thinking and need for closure were of a small effect size (Cohen, 1988). We next conducted a multiple linear regression model with belief in conspiracy theory as the criterion variable and all remaining variables entered simultaneously as predictors. Results showed that the regression model was significant, $F(7,979)=12.27, p<.001$, Adj. $R^{2}=.08$. Multicollinearity diagnostics indicated that multicollinearity was not a limiting factor in this regression model (all VIFs < 1.53). As seen in Table 2, greater belief in conspiracy theories was significantly predicted by lower analytic thinking style, greater intuitive thinking, and lower open-minded thinking.

The results of Study 1 indicate that belief in conspiracy theories is associated with individual differences in thinking dispositions. In particular, we found that stronger belief in conspiracy theories was associated with a lesser tendency to rely on deliberative, analytic processing of information and a greater tendency to rely on frugal, intuitive information processing. These findings are consistent with the suggestion that a more analytic thinking style, which is associated with more careful information processing, gives individuals the tools and space with which to critically evaluate conspiracy theories, especially those that are illogical or lacking in evidence. A more analytic thinking style is also correlated with correct normative responses on tests of cognitive bias (Epstein et al., 1996), which in turn may also contribute to lower belief in conspiracy theories. Likewise, greater open-mindedness - which is associated with analytic reasoning (Kokis et al., 2002) was associated with lower belief in conspiracy theories once the effects of other variables had been taken into account. In short, the emerging picture is one of an analytic thinking style and open-mindedness being associated with lower conspiracist ideation.

Conversely, a greater tendency to think intuitively, as opposed to emotionally or imaginatively, was associated with greater belief in conspiracy theories. The Intuition subscale of the REIm is thought to measure a general tendency to process information experientially, that is, to solve problems intuitively and based on affect (Norris \& Epstein, 2011). The association of scores on this subscale with belief in conspiracy theories is consistent with the suggestion that conspiracy theories are often affect-laden or are related to highly salient and emotive events (Sunstein \& Vermeule, 2009). In addition, to the extent that conspiracy theories thrive in situations marked by crippled epistemologies (Hardin, 2002), a greater tendency to think intuitively may promote acceptance of conspiracy theories that require low cognitive effort. Finally, an intuitive thinking style promotes a preference for heuristic solutions (Epstein et al., 1996), which in turn have been associated with greater belief in conspiracy theories (Brotherton \& French, 2014; Clarke, 2002; Leman \& Cinnirella, 2007; McHoskey, 1995).

In our multiple regression model, we found that both need for cognition and need for closure did not emerge as significant predictors of belief in conspiracy theories. These weak associations are generally consistent with previous studies reporting no significant association between belief in conspiracy theories and need for closure (Leman \& Cinnirella, 2013) and tolerance of ambiguity (AbalakinaPaap et al., 1999). It is possible that these variables affect belief in conspiracy theories indirectly (Leman \& Cinnirella, 2013); that is, they may mediate the relationship between conspiracist ideation and more distal predictors, such as Openness to Experience. This may be a fruitful avenue for future research, as would replication of the present findings with a more representative sample or samples from different cultural backgrounds. In addition, the primary limitation of Study 1 is the reliance on a correlational design, which limits our ability to draw causational conclusions. This is an issue we sought to address using an experimental methodology in Study 2.

Table 1

Descriptive statistics for, and bivariate correlations between, all variables included in Study 1.

\begin{tabular}{|c|c|c|c|c|c|c|c|c|}
\hline & (1) & (2) & (3) & (4) & (5) & (6) & $(7)$ & (8) \\
\hline $\begin{array}{l}\text { (1) Belief in conspiracy theories } \\
\text { (2) Rational thinking style } \\
\text { (3) Intuitive thinking style } \\
\text { (4) Emotional thinking style } \\
\text { (5) Imaginative thinking style } \\
\text { (6) Actively open-minded thinking } \\
\text { (7) Need for cognition } \\
\text { (8) Need for closure }\end{array}$ & & $-.25^{* *}$ & $\begin{array}{c}.21^{* *} \\
-.09^{*}\end{array}$ & $\begin{array}{c}.05 \\
-.17^{* *} \\
.25^{* *}\end{array}$ & $\begin{array}{c}.04 \\
-.13^{\text {*** }} \\
.39^{\text {*** }} \\
.37^{\text {*** }}\end{array}$ & $\begin{array}{r}-.07^{*} \\
.38^{* *} \\
-.15^{* *} \\
-.26^{* *} \\
.16^{* *}\end{array}$ & $\begin{array}{c}.01 \\
.35^{* *} \\
.01 \\
-.33^{* *} \\
-.06 \\
.46^{* *}\end{array}$ & $\begin{array}{r}.07^{*} \\
.08^{*} \\
-.08^{*} \\
.28^{* *} \\
-.09^{*} \\
.26^{* *} \\
-.11^{* *}\end{array}$ \\
\hline $\begin{array}{l}M \\
S D\end{array}$ & $\begin{array}{l}3.10 \\
1.36\end{array}$ & $\begin{array}{l}3.57 \\
0.76\end{array}$ & $\begin{array}{l}3.28 \\
0.62\end{array}$ & $\begin{array}{l}3.35 \\
0.65\end{array}$ & $\begin{array}{l}3.78 \\
0.70\end{array}$ & $\begin{array}{l}3.59 \\
0.42\end{array}$ & $\begin{array}{l}3.63 \\
0.66\end{array}$ & $\begin{array}{l}3.39 \\
0.78\end{array}$ \\
\hline
\end{tabular}

Note: $N=990$

${ }^{*} p<.05$.

* $p<.001$. 
Table 2

Standardised and unstandardised regression coefficients for the multiple linear regression conducted in Study 1 with belief in conspiracy theories as the criterion variable.

\begin{tabular}{|c|c|c|c|c|c|c|}
\hline & B & SE & $\beta$ & $t$ & $p$ & VIF \\
\hline Rational thinking style & -.42 & .07 & -.22 & -6.04 & $<.001$ & 1.29 \\
\hline Intuitive thinking style & .26 & .08 & .12 & 3.42 & .001 & 1.28 \\
\hline Emotional thinking style & .13 & .08 & .06 & 1.67 & .095 & 1.42 \\
\hline Imaginative thinking style & .16 & .12 & .05 & 1.31 & .189 & 1.53 \\
\hline Actively open-minded thinking & -.13 & .06 & -.07 & -2.08 & .038 & 1.29 \\
\hline Need for cognition & .05 & .08 & .02 & 0.63 & .531 & 1.45 \\
\hline Need for closure & .05 & .06 & .03 & 0.93 & .351 & 1.19 \\
\hline
\end{tabular}

Note $:$ VIF = Variance Inflation Factor.

\section{Study 2}

The results of Study 1 indicated that a greater tendency toward analytic thinking was the strongest predictor of belief in conspiracy theories of the variables we identified as being potentially relevant. In Study 2, we sought to establish causation by testing whether an experimental manipulation that implicitly promoted analytic processing of information would reduce belief in conspiracy theories. There are reasons to think that this manipulation should be successful and that it may be possible to reduce an individual's belief in conspiracy theories. First, previous studies have shown that informational framing influences belief in conspiracy theories, such that information that is supportive of a conspiratorial explanation promotes belief (Butler, Koopman, \& Zimbardo, 1995), whereas critical information results in an attenuation of conspiracist beliefs (Newheiser, Farias, \& Tausch, 2011; Swami et al., 2013). Indeed, Swami et al. (2013) reported that this supportive versus critical message bias had quite a large effect ( $d=1.15$ ) on subsequent agreement or disagreement with a conspiracy theory.

Additionally, Banas and Miller (2013) have shown that it is possible to inoculate against a conspiracy theory through the use of analytic, cognitively-focused communication efforts. More specifically, the authors showed that a fact-based message that dispelled some of the factual errors in a conspiracy theory was effective at inducing resistance compared to a control message. Likewise, a logic-based message that attempted to show how the conspiracy theory was not logical was also effective at inducing resistance, though not to the same extent as the factual message. Taken together, the available evidence suggests that it may be possible to reduce belief in conspiracy theories by promoting a more analytic thinking style. Because conspiracy theories often employ counter-factual arguments (e.g., circular reasoning, repetition of unproven premises, non-falsifiability, and logical flaws; Miller, 2002), promoting a tendency to think analytically should reduce agreement with unsound, illogical arguments. Analytic thinking may also impact on belief in conspiracy theories in other ways. For example, one hallmark of conspiracy theories is the notion that component events of a phenomenon and/or phenomena are causally connected (Bale, 2007). By detaching components of a phenomenon from its context and focusing attention on the attributes of each component (Nisbett, Peng, Choi, \& Norenzayan, 2001), analytic thinking may disrupt perceptions of causal connectedness inherent in conspiracist ideation.

Analogous support also comes from studies showing that analytic thinking predicts reasoning performance on laboratory tasks (Stanovich \& West, 2000), as well as belief systems; specifically, individuals who engage in analytic thinking are less likely to hold specific religious and paranormal beliefs (Gervais \& Norenzayan, 2012; Pennycook, Cheyne, Seli, Koehler, \& Fugelsang, 2012; Shenhav, Rand, \& Greene, 2012). Although analogies between religious and/or paranormal beliefs and conspiracist ideation should be drawn with extreme caution, it is possible that analytic thinking helps to disrupt belief in conspiracy theories by helping individuals detect logical conflicts inherent in such theories (cf. Pennycook et al., 2012). Implicit in this perspective is the idea that individuals who very strongly believe in conspiracy theories because they may be less likely to detect the afore-mentioned logical and reasoning fallacies.

In Study 2, then, we tested the possibility that analytic thinking attenuates conspiracist ideation by examining whether a scrambled-sentence task priming procedure would reduce belief in conspiracy theories. Recent studies have used modified versions of this priming procedure to effectively activate analytic thinking without explicit awareness on the part of participants (Gervais \& Norenzayan, 2012; Uhlmann, Poehlman, Tannenbaum, \& Bargh, 2011). Participants completed a measure of belief in conspiracy theories several weeks before and immediately after the priming task. Based on the results of previous studies (Banas \& Miller, 2013; Swami et al., 2013), as well as the findings of Study 1, we expected that participants in the analytic priming condition would show weaker belief in conspiracy theories following the experimental manipulation compared with participants in a control condition.

\subsection{Method}

\subsubsection{Participants}

The participants of this study were 112 undergraduates (66 women, 46 men) at a university in London, UK, who were randomly assigned to either the Analytic $(n=58)$ or Control $(n=54)$ prime. Participants had a mean age of 19.54 years $(S D=3.06)$ and the majority were of British White descent (75.9\%; Asian $=20.5 \%$; other $=3.6 \%$ ). 


\subsubsection{Priming task}

Participants were primed using a modified version of the scrambled-sentence verbal fluency task (Srull \& Wyer, 1979, 1980; modification: Gervais \& Norenzayan, 2012). In this task, participants were initially told they would be taking part in a 'verbal fluency' task in which they were given ten sets of five words in a nonsense order. Four of the words comprised a viable sentence and participants were instructed to drop one word and unscramble the remaining words to form a phrase (e.g., "man away postcard the walked" becomes "the man walked away"). In the Analytic condition, five of the word sets contained a target prime word related to analytic or rational reasoning (analyse, reason, ponder, think, rational). In the Control condition, the scrambled sentences contained neutral words (e.g., chair, shop).

Although the target prime words related to analytic reasoning were identical to those used in a previous study (Gervais \& Norenzayan, 2012), the additional words and final phrases were different. To ensure that this priming procedure elicited analytic processing, we conducted a pilot study with 68 undergraduates (42 women, 26 men; age $M=19.02$ years, $S D=2.96$ ) who were subsequently excluded from participation in the main study. Following Gervais and Norenzayan (2012), pilot participants were randomly assigned to complete either the Analytic prime $(n=32)$ or the Control prime $(n=36)$. They then answered the one-item Moses Illusion task (Erickson \& Mattson, 1981; 'How many of each kind of animal did Moses take on the Ark?'), a measure used to assess analytic versus experiential processing (Song \& Schwarz, 2008a). Results showed that participants were significantly more likely to respond with the correct answer (e.g., 'Moses did not have an ark' or 'Cannot say') in the Analytic condition (31\%) compared with the Control condition (8\%), $\chi^{2}(1)=5.75, p=.016$.

\subsubsection{Design and procedure}

At the start of a teaching semester, students enrolled on an introductory course in psychology were invited to participate in the study voluntarily. They completed a survey presented on a computer terminal in a private cubicle. The survey included the BCTI as described in Study 1 $(\alpha=.87)$, as well as filler scales unrelated to the present study, which we included in order to help mask the study hypothesis, and a request for participant demographics (sex, age, ethnicity). All items from the different measures were presented in a randomised order for each participant in blocks of 20 items per screen-page. As required by the ethics committee, nominal codes were used to link the data from this testing session with later data without breaching the participants' right to anonymity.

Approximately five weeks after the initial survey was completed, participants were invited to complete the second part of the study. We had a very low attrition rate: only six participants who could not be contacted at this stage were omitted from the study. Participants completed the experiment on a computer terminal in a private cubicle. All instructions were fully automated onscreen in order to minimise possible experimenter bias. As discussed by Gervais and Norenzayan (2012), participants were informed that they would be participating in several unrelated 'mini-studies' in a random order. In fact, participants completed the priming task, followed by the BCTI $(\alpha=.89)$ and distractor scales, whose items were presented in a randomised order. In a post-experiment debriefing, none of the participants correctly guessed the study hypothesis.

\subsection{Results and discussion}

Preliminary analyses showed that there were no significant differences between the Analytic and Control groups in mean age, $t(110)=1.05, p=.297, d=0.20$, the distribution of sexes, $\chi^{2}(1)=1.49, p=.222$, and the distribution of ethnic groups, $\chi^{2}(2)=4.96, p=.084$, suggesting the randomisation process was successful. We next conducted a 2 (experimental condition: Analytic versus Control) $\times 2$ (Testing Session: Pre-manipulation versus Post-manipulation) repeated-measures analysis of variance (ANOVA), where the former variable was the between-subjects factor and the latter variable the within-subjects factor. Belief in conspiracy theories was entered as the dependent variable. The ANOVA revealed a significant interaction, $F(1,110)=5.77, p=.018, \eta_{\mathrm{p}}^{2}=.05$, confirming that the experimental manipulation had an impact on belief in conspiracy theories (see Fig. 1).

During the first testing session, there was no difference in belief in conspiracy theories between participants in the Analytic $(M=3.21, S D=1.29)$ and Control $(M=3.27$, $S D=1.48$ ) conditions, $t(110)=0.23, p=.820, d=0.04$. However, after the experimental manipulation, participants in the Analytic condition $(M=2.63, S D=1.08)$ had significantly lower belief in conspiracy theories compared with participants in the Control condition $(M=3.20, S D=1.43)$, $t(110)=2.40, p=.018, d=0.46$. There was also a significant main effect of testing session, $F(1,110)=9.03, p=.003$, $\eta_{\mathrm{p}}^{2}=.08$, with a general decline in belief in conspiracy theories over time, but no main effect of experimental condition, $F(1,110)=1.94, p=.166, \eta_{\mathrm{p}}^{2}=.02$.

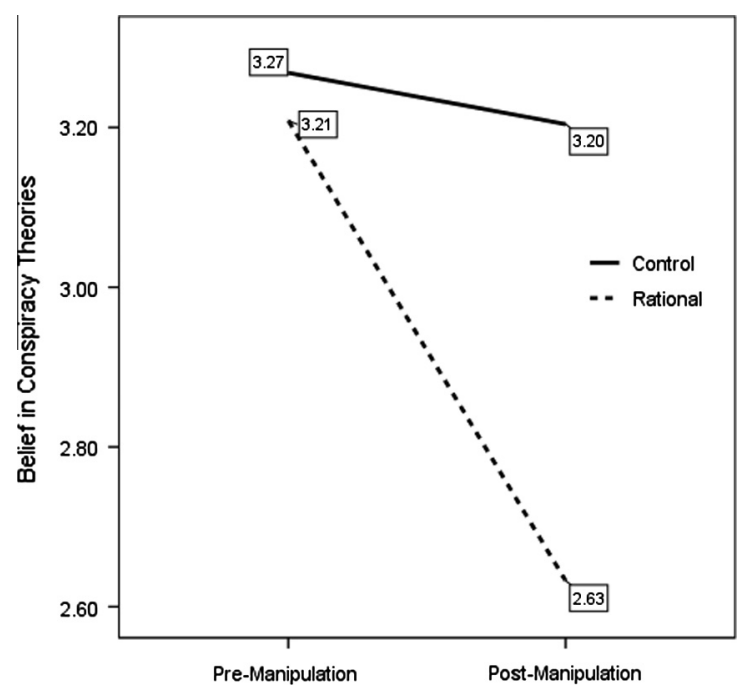

Fig. 1. Belief in conspiracy theories pre- and post-manipulation among participants in the Analytic and Control conditions in Study 2. 
The results of Study 2 provide the first evidence that an experimental manipulation designed to activate analytic thinking (Gervais \& Norenzayan, 2012; Uhlmann et al., 2011) was effective at reducing belief in conspiracy theories. Although there was no significant difference in conspiracist beliefs prior to the experimental manipulation, participants in the Analytic condition showed significantly lower belief in conspiracy theories post-manipulation compared to participants in the Control condition. In other words, implicitly priming concepts related to analytic thinking led our participants to endorse lower conspiracist beliefs. Furthermore, based on Cohen (1988), the experimental manipulation in Study 2 had a medium effect size. Furthermore, as noted by Gervais and Norenzayan (2012), one possible - though unlikely - explanation for findings such as those in Study 2 is that the act of having to perform a task (any task, not just tasks known to encourage analytic thinking) decreases belief in conspiracy theories.

\section{Study 3}

In Study 3, we sought to examine the robustness of the main finding of Study 2 that encouraging analytic thinking decreases belief in conspiracy theories. Here, we utilised an experimental manipulation that did not require participants to perform an initial task to activate analytic thinking, thereby, excluding one possible alternative explanation for the results in Study 2. Specifically, in Study 3 , we manipulated processing fluency, which previous studies have shown to be associated with analytic thinking styles. For example, presenting information in difficult-toread fonts is known to improve performance on measures of analytic thinking, including syllogistic reasoning (Alter, Oppenheimer, Epley, \& Eyre, 2007) and the Moses Illusion task (Song \& Schwarz, 2008a; see also Study 2), as well as memory tasks (Diemand-Yauman, Oppenheimer, \& Vaughan, 2011). In explanation, it has been suggested that cognitive disfluency serves to trigger analytic thinking strategies because it requires deeper processing of information (for a review, see Alter \& Oppenheimer, 2009). Following evidence that this manipulation promotes religious disbelief (Gervais \& Norenzayan, 2012), we examined whether the effect would extend to belief in conspiracy theories.

\subsection{Method}

\subsubsection{Participants}

Participants of Study 3 were 189 undergraduates (117 women, 72 men) at a university in Greater London who had a mean age of 19.72 years $(S D=4.39)$ and of whom the majority (86.0\%) were of British White descent $($ Asian $=10.0 \%$; other $=4.0 \%$.

\subsubsection{Design and procedure}

At the start of a teaching semester, students enrolled on a non-psychology course were invited to take part in the study on a voluntary basis. They completed a paper-andpencil survey packet that contained the BCTI $(\alpha=.88)$, along with a number of additional filler scales not related to the present work and a request for demographic details (sex, age, ethnicity). All items from the different scales were presented in a randomised order for each participant and, as required by the ethics committee, nominal codes were used to link participant data between testing sessions. Four weeks after completing the first survey, participants were randomly assigned to either the Control $(n=95)$ or Disfluent group $(n=94)$ and were invited to complete a second paper-and-pencil survey.

The present work followed Gervais and Norenzayan (2012) in manipulating cognitive disfluency using a difficult-to-read font. In this paradigm, participants in both conditions complete an identical survey, but presented in different formats: participants in the Control condition completed the survey in an easy-to-read, typical font, while participants in the Disfluent group completed the survey in a difficult-to-read font. Following Song and Schwarz (2008a), the easy-to-read survey used a black Arial font with font size 12 (e.g., this is a sample text), while the difficult-to-read survey used a grey Brush Script MT font with font size twelve (e.g., this is a sample text). In a pilot study, we asked 49 undergraduates (30 women, 19 men; age $M=19.99, S D=3.02$ ) who were excluded from the main study to rate the ease with which they could read the text $(1=$ Very easy, 7 = Very difficult). Confirming previous findings (Song \& Schwarz, 2008a), the Brush Script MT font $(M=5.96, S D=0.96)$ was rated as significantly more difficult to read than the Arial font $(M=4.04, S D=1.11)$, $t(47)=6.50, p<.001, d=1.90$.

In the main study, the two versions of the anonymised survey were presented to participants to be completed individually in a lecture theatre setting. Because the presentation format of instructions can affect perceptions of the difficulty of executing a behaviour, which in turn affects willingness to engage in that behaviour (Song \& Schwarz, 2008b), all participants were given the same verbal instructions by a single researcher. Additional research assistants ensured that participants did not confer while completing the surveys. The experimental survey included the BCTI $(\alpha=.90)$, as well as distractor scales not relevant to the current study. All scales were presented in a randomised order for all participants. Twelve participants who were not present on both days of testing were excluded from the study. In a post-experiment debriefing, none of the participants correctly identified the study's purpose. All participants received written debriefing information and were not remunerated for participation.

\subsection{Results and discussion}

Preliminary analyses showed that there were no significant differences between the Disfluent and Control groups in mean age, $t(187)=0.82, p=.416, d=0.12$, the distribution of sexes, $\chi^{2}(1)=2.08, p=.150$, and the distribution of ethnic groups, $\chi^{2}(2)=0.69, p=.875$. This suggests that our randomisation process was successful.

We next conducted a 2 (experimental condition: Disfluent versus Control) $\times 2$ (Testing Session: Pre-manipulation versus Post-manipulation) repeated-measures ANOVA. Belief in conspiracy theories was the dependent variable, the experimental condition was treated as a between-subjects 
factor, and testing session was treated as within-subjects factor. The ANOVA revealed a significant interaction, $F(1,187)=4.56, p=.034, \eta_{\mathrm{p}}^{2}=.02$, confirming that the experimental manipulation had an impact on belief in conspiracy theories (see Fig. 2).

At the initial testing session, there was no significant difference in belief in conspiracy theories between participants in the Disfluent $(M=3.06, S D=1.34)$ and Control $(M=3.20, S D=1.39)$ conditions, $t(187)=0.69, p=.493$, $d=0.10$. At the second testing session, however, participants who had completed the difficult-to-read survey $(M=2.66, S D=0.96)$ reported significantly lower belief in conspiracy theories compared with participants in the Control condition $(M=3.25, S D=1.40), \quad t(187)=3.38$, $p=.001, d=0.49$. There was also a significant main effect of the experimental condition, $F(1,187)=5.56, p=.019$, $\eta_{\mathrm{p}}^{2}=.03$, but no main effect of testing session, $F(1,187)=2.80, p=.096, \eta_{\mathrm{p}}^{2}=.02$.

The results of this study supported our hypothesis. That is, we found that a manipulation that increased cognitive disfluency and that has been shown to increase performance on measures of analytic thinking (Alter et al., 2007; Song \& Schwarz, 2008a) resulted in significantly lower belief in conspiracy theories. Broadly speaking, the results of Study 3 are consistent with previous work showing that the same manipulation promotes greater religious disbelief (Gervais \& Norenzayan, 2012). Taken in combination with the results of Study 2, the results of this study provide additional support for the suggestion that facilitating analytic thinking results in weaker belief in conspiracy theories.

\section{Study 4}

Although Studies 2 and 3 indicate that encouraging analytic thinking reduces belief in conspiracy theories, two issues limit the conclusions that can be drawn. First, the reliance on undergraduates in both studies limits the

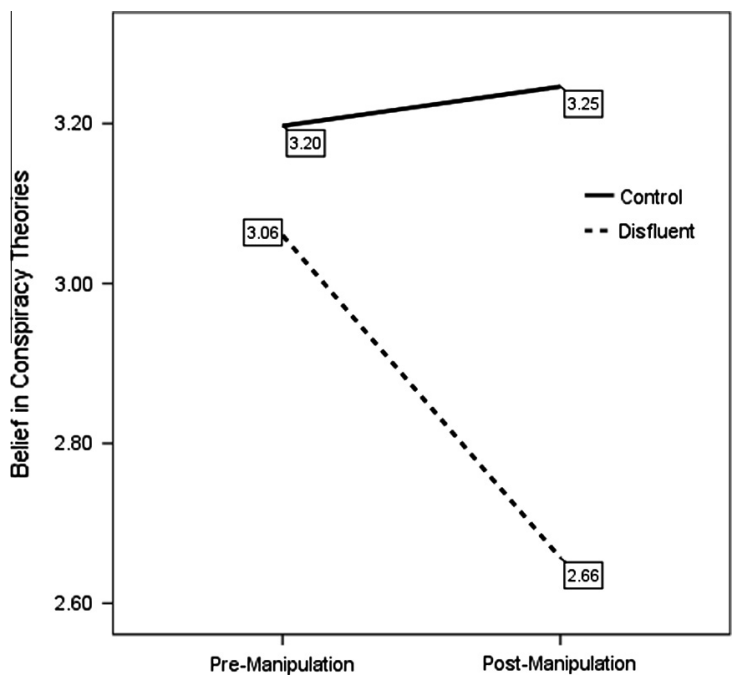

Fig. 2. Belief in conspiracy theories pre- and post-manipulation among participants in the Disfluent and Control conditions in Study 3. generalisability of our findings, especially if the greater cognitive ability among university students moderates the effects of cognitive disfluency on analytic thinking (see Thompson, Prowse Turner, Pennycook, et al., 2013; for a counter-argument, see Alter, Oppenheimer, \& Epley, 2013). Second, in Studies 2 and 3, we used a measure of general belief in conspiracy theories, and so it is possible that promoting analytic thinking reduces belief in conspiracy theories broadly, but not conspiracist ideation (although scores on the BCTI are strongly correlated with scores on a generic measure of conspiracist ideation; Brotherton et al., 2013). In Study 4, then, we examined the generalisability of the findings in Study 3 by examining the impact of encouraging analytic thinking on conspiracist ideation among a general population sample. In addition, we also included a measure of specific conspiracy theory (concerning the July 7,2005 , or $7 / 7$, bombings in London) to examine whether earlier results would extend to beliefs about a specific conspiracy theory.

\subsection{Method}

\subsubsection{Participants}

The participants of Study 4 were 66 women and 74 men recruited from the community in London, UK. Participants had a mean age of 33.87 years $(S D=15.05)$ and the majority were of British White descent (85.0\%; Asian $=13.6 \%$; African Caribbean $=1.4 \%$ ). In terms of educational qualifications, $46.4 \%$ had completed minimum secondary education, $27.9 \%$ were still in full-time education, $15.7 \%$ had an undergraduate degree, $5.7 \%$ had a postgraduate degree, and $4.3 \%$ had some other qualification.

\subsubsection{Measures}

5.1.2.1. Conspiracist ideation. All participants completed the Generic Conspiracist Beliefs Scale (GCBS; Brotherton et al., 2013). This is 15-item scale that measures individual differences in the tendency to engage in conspiracist ideation (sample item: 'A small, secret group of people is responsible for making all major world decisions, such as going to war'). Items are rated on a 5-point scale ( 1 = Definitely not true, 5 = Definitely true) and an overall score is computed as the mean of all items. Higher scores on this scale reflect greater generic conspiracist ideation. Brotherton et al. (2013) provided evidence of good psychometric properties for this scale. In the present study, Cronbach's $\alpha$ for the GCBS was .91.

5.1.2.2. Belief in $7 / 7$ conspiracy theories. To measure beliefs about a specific conspiracy theory, we used a 12-item measure of conspiracist beliefs concerning the July 7, 2005, bombings in London (Swami et al., 2011; sample item: 'The fact that the UK government is withholding information about the $7 / 7$ bombings is evidence of a cover-up'). Items are rated on a 9-point scale ( $1=$ Completely false, $9=$ Completely true). An overall score for this measure is computed as the mean of all items, with higher scores indicating greater belief that the 7/7 bombings were part of a conspiratorial act. Previous work has shown that scores on this measure are significantly correlated with scores on the GCBS ( $r=.67, N=205$; Brotherton et al., 2013) and 
the BCTI $(r=.75, N=817$; Swami et al., 2011). In the present study, Cronbach's $\alpha$ for this measure was .90 .

5.1.2.3. Analytic processing of information. As a manipulation check, we included the one-item Moses Illusion task (Erickson \& Mattson, 1981; for details, see Study 2), which assesses analytic versus experiential processing of information.

\subsubsection{Design and procedure}

In broad outline, we followed the recruitment strategy outlined in Study 1. Potential participants were invited to take part in a study on well-being and education (used as a cover for the present work) and were provided with an information sheet that contained more information about the study. Participants who agreed to take part in the study provided written informed consent and were randomly assigned to the Control $(n=66)$ or Disfluent groups $(n=74)$. All participants completed a paper-and-pencil survey, with instructions presented on a cover sheet in an easy-to-read font for all participants (so as to minimise experimenter bias). Participants in the Control group completed the survey in the same easy-to-read font (black Arial, font size 12), while the Disfluent group completed the survey in a difficult to read font (grey Brush Script MT, font size 12). The results of the pilot study in Study 3 showed that the latter font was rated as significantly more difficult to read that the former font. The survey also included several filler scales not related to the present work and included in order to minimise the potential for hypothesis-guessing. The order of presentation of all scales was pre-randomised for all participants, with a request for demographic information (sex, age, highest educational qualifications, ethnicity) always appearing last. Upon completion of the survey, participants received a debrief sheet containing further information about the study and the contact details of the first author. All participants took part on a voluntary basis and were paid $£ 1.50$ for participation.

\subsection{Results and discussion}

To check that the experimental manipulation was successful at eliciting analytic processing, we examined responses on the Moses Illusion task. Results indicated that participants were significantly more likely to respond with the correct answer in the Disfluent condition (35\%) compared with the Control condition $(12 \%), \chi^{2}(1)=10.05$, $p=.002$. In addition, there were no significant betweengroup differences on mean age, $t(138)=0.42, p=.674$, $d=0.07$, and the distribution of ethnicities, $\chi^{2}(2)=2.14$, $p=.343, \quad \phi=.12$, and educational qualifications, $\chi^{2}(4)=2.45, p=.654$. Responses on the Moses Illusion task was not significantly correlated with educational status in this sample, $r_{\mathrm{s}}=.10, p=.229$.

An independent-samples $t$-test revealed that participants in the Disfluent group $(M=2.56, S D=0.89)$ had significantly lower generic conspiracist ideation than participants in the Control group $(M=2.90, S D=0.70)$, $t(138)=2.49, p=.014, d=0.42$. Similarly, participants in the Disfluent group $(M=2.70, S D=1.20)$ had significantly lower belief in conspiracy theories of the $7 / 7$ bombings compared with participants in the Control group $(M=3.13, S D=1.34), t(138)=2.01, p=.046, d=0.34$. These results support the conclusions drawn in Studies 2 and 3 about the effects of eliciting analytic processing, but extend it to a general population sample in relation to generic conspiracist ideation and a specific conspiracy theory.

\section{General discussion}

The results of Study 1 showed that belief in conspiracy theories were associated with thinking dispositions, particularly analytic and intuitive thinking styles. More than this, further studies indicated that experimental manipulations eliciting analytic thinking were effective at reducing belief in conspiracy theories (Studies 2 and 3), generic conspiracist ideation, and belief in conspiracy theories about the 7/ 7 London bombings (Study 4). Of course, alternative explanations may be postulated to account for the results of individual studies reported here. Across all four studies, however, the most parsimonious explanation appears to be that eliciting analytic thinking reduces belief in conspiracy theories, which would be consistent with other work showing similar effects on belief systems that bear the hallmarks of experiential information processing (Gervais \& Norenzayan, 2012; Pennycook et al., 2012; Shenhav et al., 2012). Certainly, the hypothesis that analytic thinking reduces conspiracist ideation is consistent with previous experimental work (Banas \& Miller, 2013; Swami et al., 2013) and commentary (Blair, 2012; Leman, 2007).

These findings raise important questions about how specifically analytic processing of information influences belief in conspiracy theories. The most straight-forward answer to this question is that analytic thinking prompts careful and deliberate processing of information (Chaiken et al., 1989), which increases attention to the logical fallacies and factual inaccuracies inherent in most conspiracy theories. That is, analytic processing of information may inhibit intuitions and biases that support the assimilation and acceptance of conspiracy theories. For example, analytic thinking may attenuate the effects of heuristics and biases that are known to affect belief in conspiracy theories (Brotherton \& French, 2014; Leman \& Cinnirella, 2007). However, given the relatively large effects we have uncovered, it seems unlikely that this is the only way in which conspiracist ideation is inhibited.

Another way in which analytic thinking styles may affect conspiracist ideation is through the provision of space and tools with which to override any pre-existing conspiracist ideation. That is, inducing analytic thinking styles may assist individuals to re-evaluate the evidence against a conspiracist worldview in general or conspiracist statements in particular. One way of testing this in future work would be to see whether inducing analytic thinking translated into longer reaction times in responding to a measure of conspiracist beliefs. Alternatively, it may also be possible that individuals who have been primed to thinking analytically do not scrutinise all the available evidence, but rather merely select responses that appear more 'rational' to them. For example, among individuals who are uncertain about their beliefs or who have suspicions about 
conspiracy theory, the most 'rational' means of responding would be to not endorse such statements. Finally, another way of answering this question would be is to focus on conspiracy theories themselves: because conspiracy theories typically require lower cognitive effort and tend to trigger affective feelings (Swami \& Furnham, 2014), they may be more likely to appeal to an experiential thinking style.

An alternative explanation for our findings is that our results are reflective of the broad reach of analytic thinking. That is, given that our work replicates previous findings showing that analytic thinking reduces religious beliefs (Gervais \& Norenzayan, 2012), it is possible that analytic thinking boosts scepticism toward any sort of belief. In other words, analytically thinking individuals may be less willing to endorse any given statement. The fact that none of our dependent measures included reverse-coded items makes this difficult to test in the present study. Another possibility is that analytic thinking affects conspiracist ideation via mediating variables that are known to affect the latter, such as self-esteem. In a similar vein, it is also possible that the experimental methods used in our studies facilitated, not analytic thinking per se, but rather correlates of analytic thinking. To take one example, the effect of the prime in Study 2 may have been to promote improved monitoring of intuitive responses (see Thompson, Prowse Turner, \& Pennycook, 2011) or conflict detection processes (i.e., determining whether one's intuitions conflict with normative considerations; De Neys \& Glumicic, 2008). A similar criticism can be levelled at Studies 3 and 4: it is possible that unexpected moderator variables affected our results. For example, one possibility is that a hard-to-read font affects analytic thinking indirectly via diligence (Alter \& Oppenheimer, 2009); that is, in the hard-to-read condition, respondents may have been more wary and thus attended to the materials for longer and more thoroughly (Thompson et al., 2013), which in turn (and indirectly) affects analytic thinking. The possibility of unmeasured variables exerting an influence on our findings through moderator effects on analytic thinking is one that cannot be ruled out by the present studies, which in turn requires further investigation.

Furthermore, we are not suggesting that thinking dispositions are the only, or even the most important, factor to affect belief in conspiracy theories. Conspiracy theories are associated with a range of cultural, social, cognitive, and individual difference factors (for reviews, see Swami \& Coles, 2010; Swami \& Furnham, 2014) and, while the present work suggests one possible cognitive source, it will be important for future work to establish the relationship between thinking dispositions and other identified variables in shaping belief in conspiracy theories. In a similar vein, the mean responses to our measures of conspiracist ideation suggest a relatively low level of agreement with conspiracy theories across our samples. Among such respondents, analytic thinking may have had attenuating effect because of the resultant skepticism towards potentially illogical claims. By contrast, among individuals who very strongly believe in conspiracy theories, individual differences in analytic thinking may not be sufficiently pervasive to reduce conspiracist ideation. This is an issue worthy of future study, although there may be difficulties in recruiting an appropriate sample.

Furthermore, although the multiple studies suggest that our results are robust, future work could employ alternative methods of eliciting analytic thinking, such as the visual priming paradigm developed by Gervais and Norenzayan (2012) or asking participants to adopt the perspective of another (e.g., Beatty \& Thompson, 2012). In a similar vein, a useful avenue for future research would be to examine the effects of either eliciting intuitive thinking or interfering with analytic thinking on belief in conspiracy theories. Another area of our study that requires further attention is the generalisability of our findings to different cultural and political contexts. As Swami (2012) has noted, actors may adopt conspiracy theories for varying functional roles in different cultural contexts. As such, it will be important to replicate our findings in those cultural contexts where conspiracy theories serve political or socioeconomic functions not typically fulfilled in Western Europe and North America (e.g., to establish and maintain social dominance or distance; Mashuri \& Zaduqisti, 2014; Swami, 2012). Finally, if our findings are to be of practical value, it will be important to establish the extent to which engaging analytic thinking results in long-term change in conspiracist ideation. Longitudinal work and intervention-based programmes aimed at promoting analytic thinking would no doubt help to shed light on these issues.

In conclusion, the present work demonstrates that eliciting analytic thinking reduces belief in conspiracy theories, at least in the short term. Although it is widelythought that belief in conspiracy theories are resistant to change, recent work indicates that it is possible to reduce belief in conspiracy theories through the use of critical, logical, and fact-based arguments (Banas \& Miller, 2013; Swami et al., 2013). Our findings contribute to this body of work in showing that an analytic thinking style can result in decreased conspiracist ideation. More broadly, our work suggests that, if policy-makers are concerned about the negative outcomes associated with belief in conspiracy theories, supporting the development of analytic thinking skills may be a useful beginning. For scholars, understanding these associations may be an important step forward in formulating more elaborate theoretical models that explain the widespread acceptance of conspiracy theories in contemporary societies.

\section{References}

Abalakina-Paap, M., Stephan, W. G., Craig, T., \& Gregory, W. L. (1999) Beliefs in conspiracies. Political Psychology, 20, 637-647. http:// dx.doi.org/10.1111/0162-895X.00160.

Alter, A. L., \& Oppenheimer, D. M. (2009). Uniting the tribes of fluency to form a metacognitive nation. Personality and Social Psychological Review, 13, 219-235. http://dx.doi.org/10.1177/1088868309341564.

Alter, A. L., Oppenheimer, D. M., \& Epley, N. (2013). Disfluency prompts analytic thinking - But not always greater accuracy: Response to Thompson. Cognition, 128, 252-255. http://dx.doi.org/10.1016/ j.cognition.2013.01.006.

Alter, A. L., Oppenheimer, D. M., Epley, N., \& Eyre, R. N. (2007). Overcoming intuition: Metacognitive difficulty activates analytic reasoning. Journal of Experimental Psychology: General, 136, 569-576. http://dx.doi.org/10.1037/0096-3445.136.4.569. 
Baer, M. D. (2013). An enemy old and new: The Dönme, anti-Semitism, and conspiracy theories in the Ottoman Empire and the Turkish Republic. Jewish Quarterly Review, 103, 523-555. http://dx.doi.org/ 10.1353/jqp.2013.0033.

Bale, J. M. (2007). Political paranoia v. political realism: On distinguishing between bogus conspiracy theories and genuine conspiratorial politics. Patterns of Prejudice, 41, 45-60. http://dx.doi.org/10.1080/ 00313220601118751.

Banas, J. A., \& Miller, G. (2013). Inducing resistance to conspiracy theory propaganda: Testing inoculation and metainoculation strategies. Human Communication Research, 39, 184-207. http://dx.doi.org/ 10.1111/hcre.12000.

Baron, J. (2008). Thinking and deciding (4th ed.). New York: Cambridge University Press.

Barron, D., Morgan, K., Towell, T., Altemeyer, B., \& Swami, V. (2014). Associations between schizotypy and belief in conspiracist ideation. Personality and Individual Differences, 70, 156-159. http://dx.doi.org/ 10.1016/j.paid.2014.06.040.

Beatty, E. L., \& Thompson, V. A. (2012). Effects of perspective and belief on analytic reasoning in a scientific reasoning task. Thinking and Reasoning, 18, 441-460. http://dx.doi.org/10.1080/ 13546783.2012.687892.

Bilewicz, M., Winiewski, M., Kofta, M., \& Wójcik, A. (2013). Harmful ideas: The structure and consequences of anti-Semitic beliefs in Poland. Political Psychology, 34, 821-839. http://dx.doi.org/10.1111/ pops.12024.

Blair, J. A. (2012). The Keegstra affair: A test case for critical thinking. In C. W. Tindale (Ed.), Groundwork in the theory of argumentation: Selected papers of J. Anthony Blair (pp. 13-22). New York: Springer. doi: http:// dx.doi.org/10.1007/978-94-007-2363-4_2.

Bost, P. R., \& Prunier, S. G. (2013). Rationality in conspiracy beliefs: The role of perceived motive. Psychological Reports, 113, 118-128. http:// dx.doi.org/10.2466/17.04/PR0.113x17z0.

Brotherton, R., \& French, C. C. (2014). Belief in conspiracy theories and susceptibility to the conjunction fallacy. Applied Cognitive Psychology, 28, 238-248. http://dx.doi.org/10.1002/acp.2995.

Brotherton, R., French, C. C., \& Pickering, A. D. (2013). Measuring belief in conspiracy theories: The Generic Conspiracist Beliefs Scale. Frontiers in Psychology, 4, 279. http://dx.doi.org/10.3389/fpsyg.2013. 00279 .

Bruder, M., Haffke, P., Neave, N., Nouripanah, N., \& Imhoff, R. (2013). Measuring individual differences in generic beliefs in conspiracy theories across cultures: The generic conspiracist beliefs scale. Frontiers in Psychology, 4, 279. http://dx.doi.org/10.3389/ fpsyg.2013.00279.

Butler, L. D., Koopman, C., \& Zimbardo, P. G. (1995). The psychological impact of the film JFK. Political Psychology, 16, 237-257.

Cacioppo, J. T., \& Petty, R. E. (1982). The need for cognition. Journal of Personality and Social Psychology, 42, 116-131. http://dx.doi.org/ 10.1037/0022-3514.42.1.116.

Cacioppo, J. T., Petty, R. E., Feinstein, J. A., \& Jarvis, W. B. (1996). Dispositional differences in cognitive motivation: The life and times of individuals varying in need for cognition. Psychological Bulletin, 56, 81-105. http://dx.doi.org/10.1037/0033-2909.2.197.

Chaiken, S. (1980). Heuristic versus systematic information processing and the use of source versus message cues in persuasion. Journal of Personality and Social Psychology, 39, 752-756. http://dx.doi.org/ 10.1037/0022-3514.39.5.752.

Chaiken, S, Liberman, A. \& Eagly, A. H. (1989). Heuristic and systematic information processing within and beyond the persuasion context. In J. S. Uleman \& J. A. Bargh (Eds.), Unintended thought: Limits of awareness, intention, and control (pp. 212-252). New York: Guilford.

Clarke, S. (2002). Conspiracy theories and conspiracy theorizing Philosophy of the Social Sciences, 32, 131-150. http://dx.doi.org/ $10.1177 / 004931032002001$

Cohen, J. (1988). Statistical power analysis for the behavioral sciences (2nd ed.). Hillsdale, NJ: Lawrence Erlbaum.

Darwin, H., Neave, N., \& Holmes, J. (2011). Belief in conspiracy theories: The role of paranormal belief, paranoid ideation and schizotypy. Personality and Individual Differences, 50, 1289-1293. http:// dx.doi.org/10.1016/j.paid.2011.02.027.

De Neys, W., \& Glumicic, T. (2008). Conflict monitoring in dual process theories of reasoning. Cognition, 106, 1248-1299. http://dx.doi.org/ 10.1016/j.cognition.2007.06.002

Denes-Raj, V., \& Epstein, S. (1994). Conflict between intuitive and rational processing: When people behave against their better judgement. Journal of Personality and Social Psychology, 66, 819-829. http:/ dx.doi.org/10.1037/0022-3514.66.5.819.
Diemand-Yauman, C., Oppenheimer, D. M., \& Vaughan, E. B. (2011). Fortune favors the bold (and the italicized): Effects of disfluency on educational outcomes. Cognition, 118, 111-115. http://dx.doi.org/ 10.1016/j.cognition.2010.09.012.

Erickson, T. A., \& Mattson, M. E. (1981). From words to meaning: A semantic illusion. Journal of Verbal Learning and Verbal Behavior, 20, 540-552. http://dx.doi.org/10.1016/S0022-5371(81)90165-1.

Epstein, S., Pacini, R., Denes-Raj, V., \& Heier, H. (1996). Individual differences in intuitive-experiential and analytical-rational thinking styles. Journal of Personality and Social Psychology, 71, 390-405. http:// dx.doi.org/10.1037/0022-3514.71.2.390.

Ford, C. L., Wallace, S. P., Newman, S. P., Lee, S.-J., \& Cunningham, W. E. (2013). Belief in AIDS-related conspiracy theories and mistrust in the government: Relationship with HIV testing among at-risk older adults. The Gerontologist, 53, 973-984. http://dx.doi.org/10.1093/ geront/gns 192.

Furnham, A. (2013). Commercial conspiracy theories: A pilot study. Frontiers in Psychology, 4, 379. http://dx.doi.org/10.3389/ fpsyg.2013.00379.

Gaston, G. B., \& Alleyne-Green, B. (2013). The impact of African Americans' beliefs about HIV medical care on treatment adherence: A systematic review and recommendations for interventions. AIDS and Behavior, 17, 31-40. http://dx.doi.org/10.1007/s10451-0120323-X.

Gervais, W. M., \& Norenzayan, A. (2012). Analytic thinking promotes religious disbelief. Science, 336, 493-496. http://dx.doi.org/10.1126/ science.1215467.

Grzesiak-Feldman, M. (2013). The effect of high-anxiety situations on conspiracy thinking. Current Psychology, 32, 100-118. http:// dx.doi.org/10.1007/s12144-013-9165-6.

Groh, D. (1987). The temptation of conspiracy theory, or: Why do bad things happen to good people? In C. F. Graumann \& S. Moscovici (Eds.), Changing conceptions of conspiracy (pp. 1-37). New York: Springer.

Hardin, R. (2002). The crippled epistemology of extremism. In A. Breton, G. Galeotti, P. Salmon, \& R. Wintrobe (Eds.), Political extremism and rationality (pp. 3-22). Cambridge, UK: Cambridge University Press.

Hutchinson, A. B., Begley, E. B., Sullivan, P., Clark, H. A., Boyett, B. C., \& Kellerman, S. E. (2007). Conspiracy beliefs and trust in information about HIV/AIDS among minority men who have sex with men. Journal of Acquired Immune Deficiency Syndromes, 45, 603-605. http:// dx.doi.org/10.1097/QAI.0b013e318115126.

Imhoff, R., \& Bruder, M. (2013). Speaking (un-)truth to power: Conspiracy mentality as a generalised political attitude. European Journal of Personality, 28, 25-43. http://dx.doi.org/10.1002/per.1930.

Jolley, D., \& Douglas, K. M. (2014a). The social consequences of conspiracism: Exposure to conspiracy theories decreases intentions to engage in politics and to reduce one's carbon footprint. British Journal of Psychology, 105, 35-56. http://dx.doi.org/10.1111/ bjop.12018.

Jolley, D., \& Douglas, K. M. (2014b). The effects of anti-vaccine conspiracy theories on vaccination intentions. PLoS One, 9, e89177. http:// dx.doi.org/10.1371/journal.pone.0089177.

Kata, A. (2010). A postmodern Pandora's box: Anti-vaccination information on the Internet. Vaccine, 28, 1709-1716. http:// dx.doi.org/10.1016/j.vaccine.2009.12.022.

Kokis, J. V., Macpherson, R., Toplak, M. E., West, R. F., \& Stanovich, K. E. (2002). Heuristic and analytic processing: Age trends and associations with cognitive ability and cognitive styles. Journal of Experimental Child Psychology, 83, 26-52. http://dx.doi.org/10.1016/S00220965(02)00121-2.

Kruglanski, A. W. (1990). Motivations for judging and knowing: Implications for causal attribution. In E. T. Higgins \& R. M. Sorrentinio (Eds.). The handbook of motivation and cognition: Foundation of social behavior (Vol. 2, pp. 333-368). New York: Guilford.

Leman, P. J. (2007). The born conspiracy. New Scientist, 195, 35-38. http:// dx.doi.org/10.1016/S0262-4079(07)61774-6.

Leman, P. J., \& Cinnirella, M. (2007). A major event has a major cause: Evidence for the role of heuristics in reasoning about conspiracy theories. Social Psychological Review, 9, 18-28.

Leman, P. J., \& Cinnirella, M. (2013). Beliefs in conspiracy theories and the need for cognitive closure. Frontiers in Psychology, 27, 378. http:// dx.doi.org/10.3389/fpsyg.2013.00378.

Lewandowsky, S. Gignac, G. E, \& Oberauer, K. (2013). The role of conspiracist ideation and worldviews in predicting rejection of science. PLoS One, 8, e75637. http://dx.doi.org/10.1371/ journal.pone.0075637. 
Lewandowsky, S., Oberauer, K., \& Gignac, G. E. (2013). NASA faked the moon landing - Therefore, (climate) science is a hoax: An anatomy of the motivated rejection of science. Psychological Science, 24, 622-633. http://dx.doi.org/10.1177/0956797612457686.

Marsh, K. R., \& Pastor, D. A. (2011, May). Stanovich and West's (2007) Actively Open-Minded Thinking scale: An examination of factor structure. Paper presented at the annual meeting of the Association for Psychological Science, Washington, D.C.

Mashuri, A., \& Zaduqisti, E. (2014). The role of social identification, intergroup threat, and out-group derogation in explaining belief in conspiracy theory about terrorism in Indonesia. International Journal of Research Studies in Psychology, 3, 35-50. http://dx.doi.org/10.5861/ ijrsp.2013.446.

McHoskey, J. W. (1995). Case closed? On the John F. Kennedy assassination: Biased assimilation of evidence and attitude polarization. Basic and Applied Social Psychology, 17, 395-409. http:// dx.doi.org/10.1207/s15324834basp1703_7.

Miller, S. (2002). Conspiracy theories: Public arguments as coded social critiques: A rhetorical analysis of the TWA flight 800 conspiracy theories. Argumentation and Advocacy, 39, 40-56. http://dx.doi.org/ $10.1177 / 0267323111433566$.

Newheiser, A.-K., Farias, M., \& Tausch, N. (2011). The functioning nature of conspiracy beliefs: Examining the underpinnings of beliefs in the $\mathrm{Da}$ Vinci Code conspiracy. Personality and Individual Differences, 51 1007-1011. http://dx.doi.org/10.1016/j.paid.2011.08.011.

Nisbett, R. E., Peng, K., Choi, I., \& Norenzayan, A. (2001). Culture and systems of thought: Holistic vs. analytic cognition. Psychological Review, 108, 291-310. http://dx.doi.org/10.1037//0033295X.108.2.291.

Norris, P., \& Epstein, S. (2011). An experiential thinking style: Its facets and relations with objective and subjective criterion measures. Journal of Personality, 79, 1043-1079. http://dx.doi.org/10.1111/ j.1467-6494.2011.00718.x.

Oliver, J. E., \& Wood, T. J. (2014a). Conspiracy theories and the paranoid style(s) of mass opinion. American Journal of Political Science. http:// dx.doi.org/10.1111/ajps.12084.

Oliver, J. E., \& Wood, T. J. (2014b). Medical conspiracy theories and health behaviors in the United States. JAMA Internal Medicine. http:// dx.doi.org/10.1001/jamainternmed.2014.190.

Pacini, R., \& Epstein, S. (1999). The relation of rational and experiential information processing styles to personality, basic beliefs, and the ratio-bias phenomenon. Journal of Personality and Social Psychology, 76, 972-987. http://dx.doi.org/10.1037/0022-3514.76.6.972.

Pacini, R., Muir, F., \& Epstein, S. (1998). Depressive realism from the perspective of cognitive-experiential self-theory. Journal of Personality and Social Psychology, 74, 1056-1068. http://dx.doi.org/10.1037/ 0022-3514.74.4.1056.

Peltier, J. W., \& Schibrowsky, J. A. (1994). Need for cognition, advertisement viewing time, and memory for advertising stimuli. Advances in Consumer Research, 21, 244-250.

Pennycook, G., Cheyne, J. A., Seli, P., Koehler, D. J., \& Fugelsang, J. A. (2012) Analytic cognitive style predicts religious and paranormal belief. Cognition, 123, 335-346. http://dx.doi.org/10.1016/ j.cognition.2012.03.003.

Perkins, D. N., Tishman, S., Ritchhart, R., Donis, K., \& Andrade, A. (2000). Intelligence in the wild: A dispositional view of intellectual traits. Educational Psychology Review, 12, 269-293. http://dx.doi.org/ 10.1023/A:1009031605464.

Petty, R. E., \& Cacioppo, J. T. (1984). Source factors and the elaboration likelihood model of persuasion. Advances in Consumer Research, 11, $668-672$.

Raab, M. H., Auer, N., Ortlieb, S. A., \& Carbon, C.-C. (2013). The Sarrazin effect: The presence of absurd statements in conspiracy theories makes canonical information less plausible. Frontiers in Psychology, 4 453. http://dx.doi.org/10.3389/fpsyg.2013.00453.

Robins, R. S., \& Post, J. M. (1997). Political paranoia. New Haven, CT: Yale University Press.

Roets, A., \& van Hiel, A. (2007). Separating ability from need: Clarifying the dimensional structure of the Need for Closure Scale. Personality and Social Psychology Bulletin, 33, 266-280. http://dx.doi.org/10.1177/ 0146167206294744

Roets, A., \& van Hiel, A. (2011). Item selection and validation of a brief, 15item version of the Need for Closure Scale. Personality and Individua Differences, 50, 90-94. http://dx.doi.org/10.1016/j.paid.2010.09.004.

Sá, W. C., West, R. F., \& Stanovich, K. E. (1999). The domain specificity and generality of belief bias: Searching for generalizable critical thinking skill. Journal of Educational Psychology, 91, 497-510. http://dx.doi.org 10.1037/0022-0663.91.3497.
Sapountzis, A., \& Condor, S. (2013). Conspiracy accounts as intergroup theories: Challenging dominant understandings of social power and political legitimacy. Political Psychology, 34, 731-752. http:// dx.doi.org/10.1111/pops.12015.

Shenhav, A., Rand, D. G., \& Greene, J. D. (2012). Divine intuition: Cognitive style influences belief in god. Journal of Experimental Psychology: General, 141, 423-428. http://dx.doi.org/10.1037/a0025391.

Song, H., \& Schwarz, N. (2008a). Fluency and the detection of misleading questions: Low processing fluency attenuates the Moses illusion. Social Cognition, 26, 791-799. http://dx.doi.org/10.1521/ soco.2008.26.6.791.

Song, H., \& Schwarz, N. (2008b). If it's hard to read, it's hard to do: Processing fluency affects effort prediction and motivation. Psychological Science, 19, 986-988. http://dx.doi.org/10.1111/j.14679280.2008.02189.x.

Srull, T. K., \& Wyer, R. S. (1979). The role of category accessibility in the interpretation of information about persons: Some determinants and implications. Journal of Personality and Social Psychology, 37. 1660-1672. http://dx.doi.org/10.1037/0022-3514.37.10.1660.

Srull, T. K., \& Wyer, R. S. (1980). Category accessibility and social perception: Some implications for the study of person memory and interpersonal judgments. Journal of Personality and Social Psychology, 38, 841-856. http://dx.doi.org/10.1037/0022-3514.38.6.841.

Stanovich, K. E., \& West, R. F. (1997). Reasoning independently of prior belief and individual differences in actively open-minded thinking. Journal of Educational Psychology, 89, 342-357. http://dx.doi.org 10.1037/0022-0663.89.2.342.

Stanovich, K. E., \& West, R. F. (1999). Discrepancies between normative and descriptive models of decision making and the understanding/ acceptance principle. Cognitive Psychology, 38, 349-385. http:// dx.doi.org/10.1006/cogp.1998.0700.

Stanovich, K. E., \& West, R. F. (2000). Individual differences in reasoning: Implications for the rationality debate? Behavioral and Brain Sciences, 23, 645-665. http://dx.doi.org/10.1017/S0140525X00003435.

Stanovich, K. E., \& West, R. F. (2007). Natural myside bias is independent of cognitive ability. Thinking and Reasoning, 13, 225-247. http:// dx.doi.org/10.1080/13546780600780796.

Sunstein, C. R., \& Vermeule, A. (2009). Conspiracy theories: Causes and cures. Journal of Political Philosophy, 17, 202-227. http://dx.doi.org/ 10.1111/j.1467-9760.2008.00325.x.

Stieger, S., Gumhalter, N., Tran, U. S., Voracek, M., \& Swami, V. (2013). Girl in the cellar: A repeated cross-sectional investigation of belief in conspiracy theories about the kidnapping of Natascha Kampusch. Frontiers in Psychology, 4, 297. http://dx.doi.org/10.3389/ fpsyg.2013.00297.

Swami, V. (2012). Social psychological origins of conspiracy theories: The case of the Jewish conspiracy theory in Malaysia. Frontiers in Psychology, 3, 280. http://dx.doi.org/10.3389/fpsyg.2012.00280.

Swami, V., Chamorro-Premuzic, T., \& Furnham, A. (2010). Unanswered questions: A preliminary investigation of personality and individual difference predictors of 9/11 conspiracist beliefs. Applied Cognitive Psychology, 24, 749-761. http://dx.doi.org/10.1002/acp.1583.

Swami, V., \& Coles, R. (2010). The truth is out there: Belief in conspiracy theories. The Psychologist, 23, 560-563.

Swami, V., Coles, R., Stieger, S., Pietschnig, J., Furnham, A., Rehim, S., et al. (2011). Conspiracist ideation in Britain and Austria: Evidence of a monological belief system and associations between individual psychological differences and real-world and fictitious conspiracy theories. British Journal of Psychology, 102, 443-463. http://dx.doi.org/ 10.1111/j.2044-8295.2010.02004.x.

Swami, V., \& Furnham, A. (2012). Examining conspiracist beliefs about the disappearance of Amelia Earhart. The Journal of General Psychology, 139, 244-259. http://dx.doi.org/10.1080/00221309.2012. 697932.

Swami, V., \& Furnham, A. (2014). Political paranoia and conspiracy theories. In J.-P. Prooijen \& P. A. M. van Lange (Eds.), Power politics, and paranoia: Why people are suspicious of their leaders (pp. 218-236). Cambridge: Cambridge University Press.

Swami, V., Nader, I. W., Pietschnig, J., Stieger, S., Tran, U. S., \& Voracek, M. (2012). Personality and individual difference correlates of attitudes toward human rights and civil liberties. Personality and Individual Differences, 53, 443-447. http://dx.doi.org/10.1016/ j.paid.2012.04.015

Swami, V., Pietschnig, J., Tran, U. S., Nader, I. W., Stieger, S., \& Voracek, M. (2013). Lunar lies: The impact of informational framing and individual differences in shaping conspiracist beliefs about the moon landings. Applied Cognitive Psychology, 27, 71-80. http:// dx.doi.org/10.1002/acp.2873. 
Thompson, V. A., Prowse Turner, J. A., \& Pennycook, G. (2011). Intuition, reason, and metacognition. Cognitive Psychology, 63, 107-140. http:// dx.doi.org/10.1016/j.cogpsych.2011.06.011.

Thompson, V. A., Prowse Turner, J. A., Pennycook, G., Ball, L. J., Brack, H., et al. (2013). The role of answer fluency and perceptual fluency as metacognitive cues for initiating analytic thinking. Cognition, 128, 237-251. http://dx.doi.org/10.1016/j.cognition.2012.09.012.

Uhlmann, E. L., Poehlman, T. A., Tannenbaum, D., \& Bargh, J. A. (2011). Implicit puritanism in American moral cognition. Journal of Experimental Social Psychology, 47, 312-320. http://dx.doi.org/ 10.1016/j.jesp.2010.10.013.

van Prooijen, J.-W., \& Jostmann, N. B. (2013). Belief in conspiracy theories: The influence of uncertainty and perceived morality. European Journal of Social Psychology, 43, 109-115 (10.1002.ejsp.1922).

Warner, B. R., \& Neville-Shepard, R. (2014). Echoes of a conspiracy: Birthers, truthers, and the cultivation of extremism. Communication
Quarterly, 62, 1-17. http://dx.doi.org/10.1080/01463373.2013. 822407.

West, R. F., Toplak, M. E., \& Stanovich, K. E. (2008). Heuristics and biases as measures of critical thinking: Associations with cognitive ability and thinking dispositions. Journal of Educational Psychology, 100, 930-941. http://dx.doi.org/10.1037/a0012842.

Wood, M. J., \& Douglas, K. M. (2013). "What about Building 7?" A social psychological study of online discussion of 9/11 conspiracy theories. Frontiers in Psychology, 4, 409. http://dx.doi.org/10.3389/fpsyg. 2013.00409.

Wood, M. J., Douglas, K. M., \& Sutton, R. M. (2012). Dead and alive: Beliefs in contradictory conspiracy theories. Social Psychological and Personality Science, 3, 767-773. http://dx.doi.org/10.1177/ 1948550611434786. 